\title{
Educating About and For the Future
}

\author{
Deanna Kuhn
}

\begin{abstract}
Education for citizenship is more important than ever. The author describes a technology-supported curriculum that engages young teens in electronic discourse with peers on significant personal and societal issues and assists them in decision making on topics ranging from their personal futures to the futures of their communities, nation, and world. A further purpose is to use discourse as a bridge in developing the individual argumentive writing that students of all ages find so challenging.
\end{abstract}

\section{Background}

With the world in increasing turmoil, what could be a more important educational mission than preparing students to address the critical issues that will confront their generation as adults? Yet few pre-college classrooms engage students in debate of serious issues of the day, arguably the best practice to prepare them to address such issues as adults. Education for thinking, a foundation for citizenship, is widely viewed favorably in principle, but remains shortchanged in practice.

The social studies curriculum would seem the natural place for students to debate issues of concern to the society they live in, but doing so is largely crowded out by the traditional curriculum, regrettably not much of which sticks. (A recent Facebook video showed US college students clueless when asked who won the Civil War.) The implicit message teachers convey is that knowing about the past warrants more attention than contemplating the present or future.

Why not address the future? It surely deserves as much attention as the past. If future 21 st century citizens are going to think deeply about the issues that will face them, rather than rely on the slogans and sound bites that too often pass for thinking today, they need the practice that will prepare them to do so. And in making reasoned decisions about important issues affecting their individual and collective lives, they will develop identities as citizens with the capability and recognized responsibility to do so.

These are the considerations that led to our development of a technology-supported curriculum to develop argumentation skills in middle- and high-school students through their engagement in electronic debate with peers regarding authentic contemporary social and socio-scientific issues. It is described in a book for teachers, with embedded video illustrations, Argue With Me (Kuhn, Hemberger, \& Khait, 2016), and in a new book, Building Our Best Future: Thinking Critically About Ourselves and Our World (Kuhn, 2018), written directly to 6th-12th-grade students. In the latter, students choose from suggested topics under the headings $A$ Personal Future (e.g., When you finish high school, you have the choice of going right to college or of working for a few years first), A Community Future (e.g., Should all teachers 
receive the same pay or should teachers with more skill or experience be paid more?), A National Future (e.g., Should people pay a social security tax from each paycheck to provide money when they retire, or should people save on their own for their retirement?), and A World Future (e.g., Should a powerful nation intervene to help another nation in trouble or focus only on its own problems?). Each such issue they engage deeply in a variety of formats in collaboration with their peers.

Are typical young adolescents, including even the many academically disadvantaged ones, underserved by inadequate schools, capable of addressing such questions? Our experience documents that they are eager to do so and thrive in a context that is student-, rather than teacher-centered, and in which they develop for themselves with time the norms that govern serious discourse. But their range of experience and awareness needs gradually to expand. I asked a class of inner-city middle schoolers before the 2016 US presidential election what the major problems were that the new president would face, and most identified just two: homelessness and stealing. On the topic of allowing use of animals in research, middle-schoolers we've observed often come up with the idea that human prisoners would be a better choice for this purpose since they are guilty and animals are innocent. But such ideas self-correct with continued discussion, without heavy-handed intervention by the adults who largely play a coach role. And they gradually broaden their knowledge, in ways I describe shortly.

\section{A Technology-Based Argumentation Curriculum}

Our approach to developing argumentation skills, and the values to support them, is based on the view that this development necessitates sustained and dense practice in rich environments that require those skills and values. It requires both a supportive community and the strengthening of individual skills and understanding. Hence it is not quickly achieved.

Core features of the method are that it is student-centered, emphasizing peer-to-peer, rather than teachercentered interaction, and technology-based, although of a low-tech sort no classroom teacher would be intimidated by. Underlying it is a commitment to the view that high-level intellectual skills such as argumentation are sufficiently important to warrant dedicated attention in their own right as curriculum goals. Our approach is consistent with the sociocultural tradition of Vygotsky (1978) and other more contemporary authors (Resnick, Michaels, \& O'Connor, 2010) in taking the everyday social practice of argumentation as a starting point and pathway for development of individual argumentive thinking and writing. In Vygotsky's terminology, the inter-mental with practice becomes interiorized and transformed into the intra-mental.

Students engage deeply with a series of challenging topics, each one over as many as 12-13 class sessions. They engage in two forms of peer discourse, the first one verbal and beginning with same-side peers who prepare for dialogs with successive opposing-side peers that follow. The same-side pair must agree in advance on what to communicate to the opposing pair. This essentially doubles the participation in reasoned discourse (both verbal within the same-side pair and electronic between opposing pairs). Both types provide an opportunity for metacognitive planning and reflection (since the pair must reflect on the opponents' statements and debate what to say to them in return). 
The technology dimension of the curriculum comes into play with the second form of discourse. It centers around dialogs conducted electronically between the same-side pair and a succession of opposing pairs. Most students are already very familiar with electronic communication and they enjoy having it brought into the classroom. Yet that is not our primary reason for employing it. Electronic discourse provides a written record that externalizes thought into a tangible form, in contrast to verbal discourse, which disappears as soon as uttered. The electronic medium thus facilitates reflection on what is exchanged, taking discourse temporarily "off line" (Olson \& Oatley, 2014). In addition to serving as a reference point and framework during the dialogs, these transcripts become the object of various reflective activities that students engage in (Figures $1 \& 2$ ). The sequence of activities culminates in a whole-class "Showdown" debate, debrief analysis of the debate, and, last of all, individual final essays on the topic, in the form of a newspaper op ed.

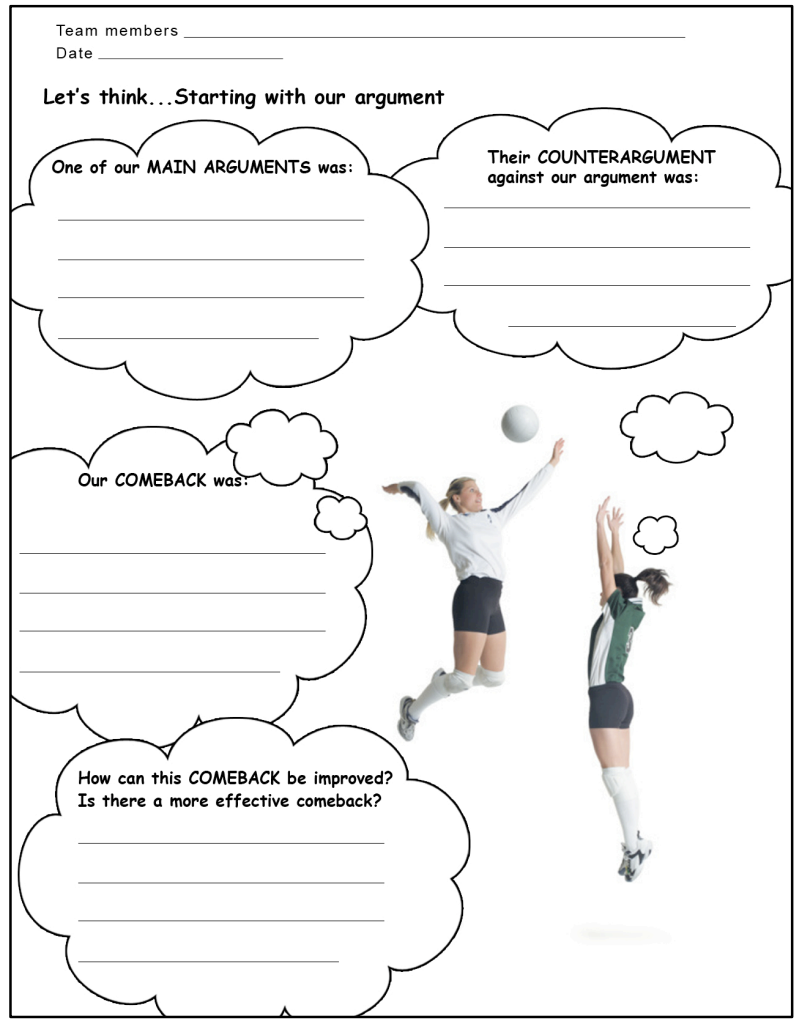

Fig 1: Own-side reflection sheet

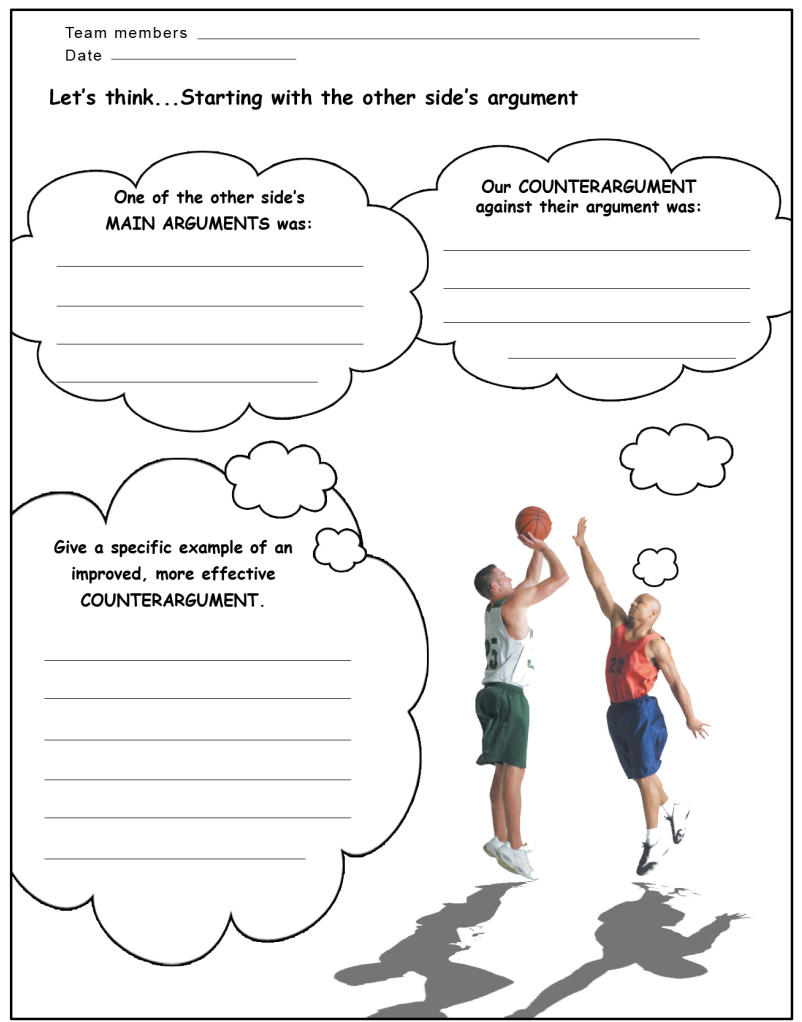

Fig. 2: Other-side reflection sheet

In their discourse with one another, students will not be able to generate rich arguments and counterarguments in a vacuum. They need to bring to bear information relevant to the topic to inform their reasoning. They will likely already have some degree of knowledge that they are ready to summon to support their arguments (or to weaken those of their opponents). But they will need more knowledge than they have at the outset. One approach might be to ask students to begin their work on a topic by reading material about it. A drawback of this approach is that students don't yet appreciate the purpose that this information serves. In a word, it provides answers to questions they don't yet have. 
As a result, they fail to see its point. They are thus likely to approach such reading disinterestedly, as just another reading assignment to complete.

A small dose of initial reading can be productive, to arouse interest in the topic, but at the outset we employ it sparingly out of concern that a deluge of information up front not only is met with disinterest, but can also shut down students' own thinking and inquisitiveness about a topic. Therefore, we let students' own ideas dominate at the beginning of their engagement with a new topic, encouraging them to articulate and share with one another their ideas about the topic. And, we have found, they do have lots of ideas to share, even in the case of topics outside the range of their immediate experience.

Still, students' discourse needs to be informed and enriched by information new to them bearing on the topic. An effective way to do this, we have found, is to first create a need for the information they acquire. Rather than provide answers to questions students don't have, we have them first formulate the questions. In this way, we allow students to first see how such information could be useful, and then we assist them in securing it. Hence, after introducing a few basic questions and answers regarding the topic, we invite students to generate questions of their own, the answers to which they think might be helpful. By the next session, we then make available brief factual answers to these questions (which students may assist in obtaining), and the resulting question-and-answer "evidence set" (containing all questions and answers) is made available for use by the entire class throughout their work on the topic. The point is for students not just to acquire information, but to see its value (Figure 3a) and therefore be disposed to apply it (Figure 3b). With practice, we have found, students do in fact in time make much use of this information, coming to recognize it as playing a critical role in their discourse.

\section{Knowledge}

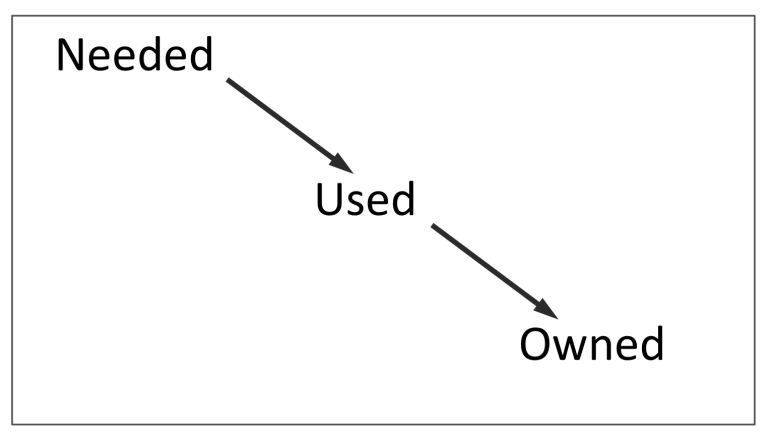

Fig. 3a: Value of information

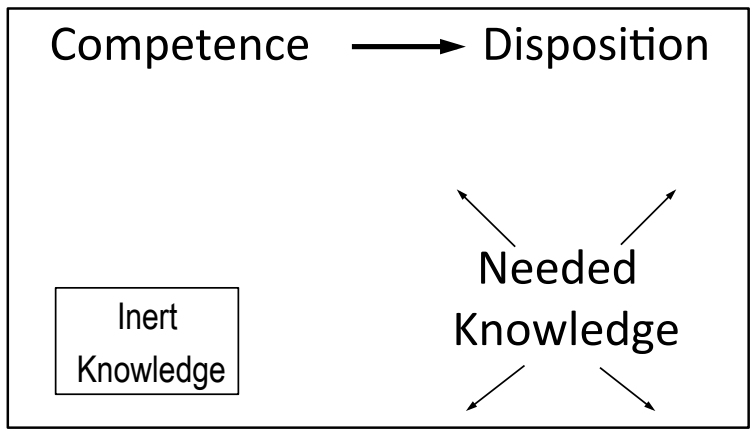

Fig. 3b: Application of information

That activities center around peer interchange (Figure 4), rather than whole-class, teacher-directed talk (Figure 5), helps to promote the objective of students becoming accountable to one another, as members of a community with evolving group norms. Students are constantly on call, needing to respond to one another. In whole-class discussion, in sharp contrast, students can fade in and out, raising a hand now and then, but the rest of the time assuming the passive role of audience. These evolving norms are constructed within the group and gain acceptance as expected behavior on the part of its members. Claims are expected to have reasons and these reasons must stand to the challenge of strong arguments and evidence that may 
weaken them. Shared understandings evolve of what acceptable counterarguments consist of and what counts as evidence, and group members risk criticism for violating them.

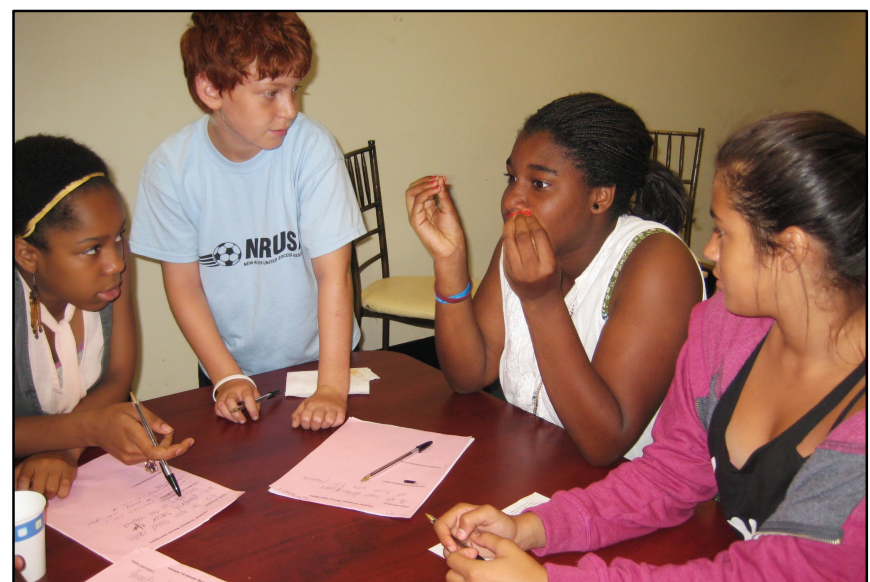

Fig. 4: Peer interchange activities

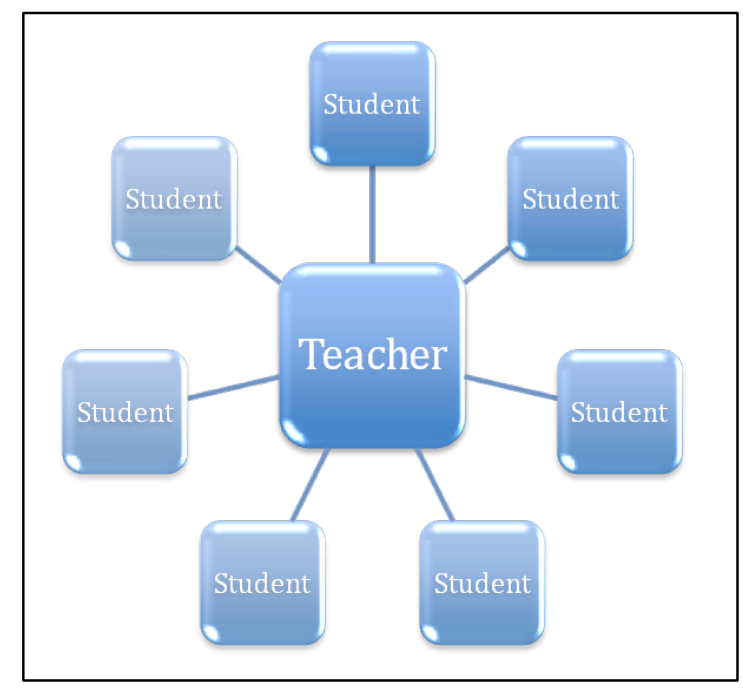

Fig. 5: Teacher-directed talk

\section{Argumentive Writing}

Students of all ages find expository writing notoriously difficult. Why is our dialogic method successful in yielding essays like that of the middle schooler's illustrated in Table 5? We believe this is so because our dialogic focus supports the development of individual written argument by giving the latter a purpose. In addition to the final "position" piece they write individually at the conclusion of a topic, students write regularly in their electronic communications to opposing pairs. This writing has a very specific and focused communicative purpose. Students also have the support of a same-side partner to collaborate with, as well as a context in which to reflect together on what they are going to say to an opposing pair.

All of these factors, our studies have suggested, contribute to students' success when they are asked to write a more conventional individual essay. Experiencing a flesh-and-blood interlocutor and a purpose to the exchange they engage in leads the way for students to interiorize this dialogic frame when it comes time for them to express themselves individually in writing. Students are no longer writing to or for a teacher, seeking to produce what they think the teacher is looking for. Instead, they engage with their peers-first electronically and then in person. Later, in individual writing, this discourse remains alive, although confined now to their own thought, when they envision what another might say and how they can address it. The dialogic structure apparent in the essay seems key. The continuing experience of dialog with a succession of peers holding the opposing position makes the opposing position and its accompanying arguments clear and vivid enough so that the student writing an individual essay can represent them in the essay and address them, and, moreover, sees the relevance of doing so. 


\section{Evidence for Effectiveness}

Of interventions that have been introduced to promote development of K-!2 students' argumentation skills, we believe ours to be among a very few having the soundest, most extensive documentation of outcomes. We have implemented the program for periods of up to three school years at five New York City public middle schools, as well as in schools in several locations outside the US. Our most extensive database comes from a Harlem school in which a total of 12 classes worked with us for two class periods each week for two to three years. Of the three class sections in each cohort, two participated in our curriculum. The third section participated in a comparison class equivalent in time and work investment but following a more traditional whole-class discussion format, along with writing assignments and some role-playing activities, based loosely on a Philosophy for Children model (Lipman, 2003).

Discourse. At annual assessments, a pair who held opposing views on a topic not part of the curriculum conducted a dialog via a "Pass-the-Pad" method (the written document passed back and forth the pair's only mode of communication) used so as not to handicap the comparison group, whose activities didn't include electronic discourse.

We classified each statement students made in the Pass-the-Pad document according to whether it "countered" the partner's immediately preceding statement. These proportions rose with each yearly assessment among the participating group, but not among the comparison group (Figure 6). Importantly, when these gains are broken down by initial skill level, the one third of the dialogic group that showed least skill at the initial assessment continued to improve during the third year to almost the level of their initially more able classmates, establishing not only that the curriculum works, but that it also works very well for low-performing students.

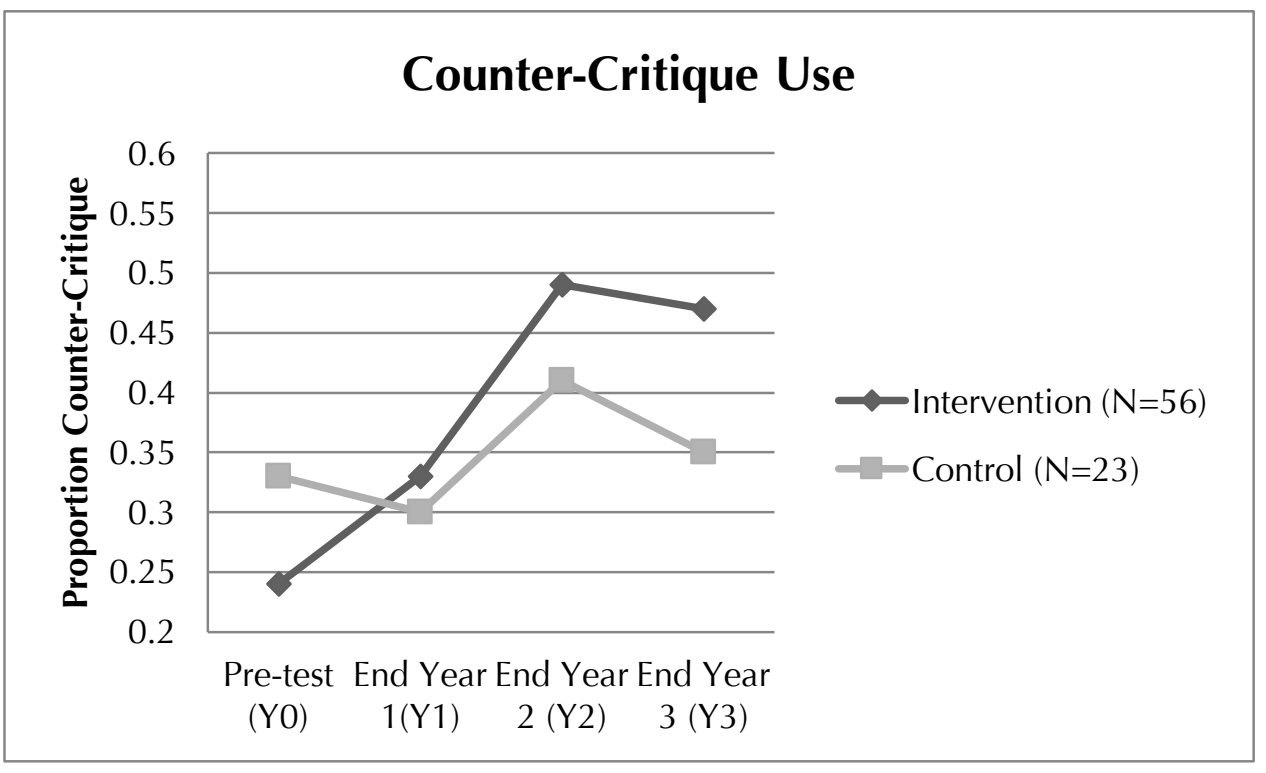

Fig. 6: Development of dialogic argument skills over time (from Crowell \& Kuhn, 2014) 
Equally revealing are our qualitative data indicating the extent to which students who began with shallow electronic exchanges, mixing substantive exchanges with meta-talk about what they were doing (Table 1) came to uphold norms of discourse with respect to both the same-side verbal discourse (Table 2) and their electronic discourse with opponents (Table 3; Kuhn \& Zillmer, 2015; Kuhn, Zillmer, Crowell, \& Zavala, 2013). As further evidence of the power of a dialogic method, direct comparisons of students' electronic discourse and their individual writing showed two differences. In discourse, they more often brought their own knowledge to bear and they more often addressed the opposing position (Kuhn \& Moore, 2015).

Individual writing. We also have documented gains in students' evaluation of arguments and in their construction of hypothetical two-sided dialogic arguments (Kuhn et al., 2013), but the outcome measure of greatest interest to educators is students' individual argumentive essays, where they also show gains (Kuhn \& Crowell, 2011; Hemberger, Kuhn, Matos, \& Shi, 2017). At annual assessments, students wrote an essay on a new topic. Gains were evident both over time and relative to the comparison class, for both dialogs and essays (Table 4). Details are available in these publications and in summary in Kuhn et al. (2016) and Kuhn (2018).

\section{Conclusions}

The seeming success of our approach by no means implies that other approaches are misguided. Standing in contrast to our experiential pedagogical emphasis are approaches that advocate explicit instruction as a tool in developing critical thinking and writing. Moreover, there now exist a number of electronic tools designed to scaffold students' efforts in constructing and evaluating arguments. There is no reason to think that explicit writing instruction will not be of additional benefit to students in further developing their argumentive writing. Indeed, the metacognitive reflection on their dialogic exchanges that our intervention encourages should help to prepare students for explicit reflection on their writing. We see our approach, rather, as addressing the building blocks of argumentive thinking and writing, and here we see extended engagement and practice as the essential foundation.

Another contrast has to do with the goals of argumentive writing, specifically whether the emphasis should be an adversarial or a consensus seeking one. Some researchers have advocated consensusseeking as the more productive objective (Scardamalia \& Bereiter, 2014; Felton, Crowell, \& Liu, 2015). However, other researchers have presented evidence that an adversarial form is more productive (Iordanou \& Constantinou, 2015). Our view has been that the adversarial frame prepares for the consensus-seeking, by sharpening relations between claims, but this is a question that warrants further investigation.

We are currently involved in further study of our method in which we subtract different features of the intervention in order to isolate which of its characteristics contribute most greatly to its strength. For now, we can say only that we believe its success is attributable to its two core features. 
One is its roots in dialog and the other is the deep engagement with significant topics that the young students who participate experience.

The mention of significant topics leads us back to the concerns introduced at the outset. Young people need to engage individually and with one another in contemplating the significant issues of their time, not only for its dividends in developing their minds. It is also critical in developing their skills and responsibilities having to do with citizenship. A point of view is indeed likely to be missing to the extent that it has never been exercised (Figure 6). The reasoned discourse of today's young people will be urgently needed in coming decades, and we should do all we can to develop it.

\section{Table 1}

Electronic dialog between two pairs early in the intervention

H1. hi, who is this? why are you for the town school? Are you on yet?

T1. yes im on are u on

H2. state your case

T2. nick should go to town becuz he needs to learn

H3. Even though he needs to learn he will hard time because he doesn't speak english

T3. he can learn english over there

H4. but his parents would still be better teachers because they know him better, by the way we're ashley and nancy

T4. I no ur ashley and im jeffrey and eduardo if the parents are teaching him they wont get enough money to buy thier food for the family

H5. Are you at lost for word and who is your partner the parents could work at the school or get the money from the government

T5. No its jeffrey and eduardo what if the government doesnt give any money or dont give enough

H6. is eduardo contributing? 


\section{Table 2}

Sample of mid-intervention verbal dialog between same-side partners

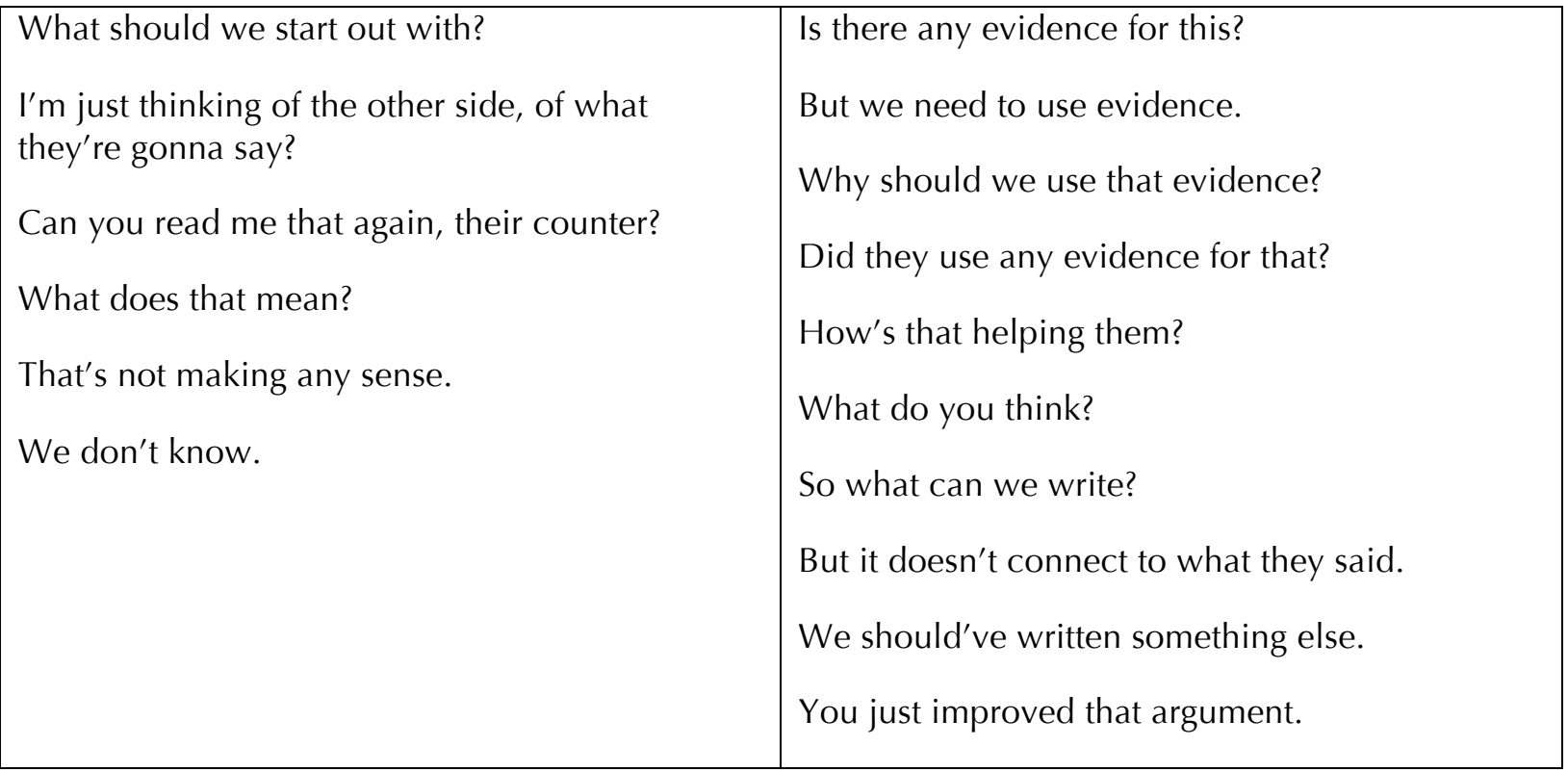

\section{Table 3}

Sample of late-intervention electronic dialog between opposing pairs

A: you can't prove that.

B: we have evidence

A: where is it? Tell us then.

Y Your argument is faulty. There is no evidence.

口 I said "may", which indicates that I do not know if they are.

- There is no proven evidence for your statement and you are using examples from your personal life that might not apply to everyone.

You are only looking at one perspective, which is the negative side of adult systems. You aren't looking at it both ways.

What I'm saying is that you aren't seeing both sides of the argument. 
Table 4a

Percentages of participants making dual-perspective and integrative arguments by time and condition (teacher pay essay, initial sample)

\begin{tabular}{|l|c|c|c|c|c|c|c|c|}
\multicolumn{1}{c|}{} & \multicolumn{2}{c|}{ Initial } & \multicolumn{2}{c|}{ Year 1 } & \multicolumn{2}{c|}{ Year 2 } & \multicolumn{2}{c|}{ Year 3 } \\
\cline { 2 - 10 } \multicolumn{1}{c|}{} & E & C & E & C & E & C & E & C \\
\hline Dual-perspective arguments & 35 & 35 & 67 & 38 & 79 & 19 & 79 & 29 \\
\hline Integrative arguments & 00 & 00 & 00 & 00 & 00 & 00 & 30 & 00 \\
\hline
\end{tabular}

Table 4b

Percentages of participants making dual-perspective and integrative arguments (teacher pay essay, replication sample)

\begin{tabular}{|c|c|c|c|c|}
\hline & \multicolumn{3}{|c|}{ Experimental group } & $\begin{array}{c}\text { Comparison } \\
\text { group }\end{array}$ \\
\hline & Initial & Year 1 & Year 2 & Year 2 \\
\hline Dual-perspective arguments & 30 & 54 & 73 & 38 \\
\hline Integrative arguments & 00 & 03 & 14 & 00 \\
\hline
\end{tabular}

Note: Sample size is 37 experimental and 21 comparison. E=Experimental; $\mathrm{C}=$ Comparison (From Kuhn \& Crowell, 2011).

Table 5

Sample final essay

- $[\mathrm{S} 30]$ I think that Juveniles should be sent to a juvenile court because of the immaturity they still have $[M+1]$. For example, a human's prefrontal cortex isn't fully developed until the age of 25, therefore they still don't have the full "intelligence" to make completely well thought out intelligent decisions until then $[\mathrm{M}+1]$. On the adult side of the argument they argued that the brain doesn't have to be fully developed to make educated decisions ${ }_{[\mathrm{O}+1]}$ they are smart enough to understand right from wrong $[\mathrm{O}+2]$. Also, in adult court it is the same as in juvenile court, you go to court, there is a jury and there is a judge that tells you if you are "guilty" or "not guilty". In response to that, they may be the same court-wise $[\mathrm{O}+3]$ but the consequences given are very different in both. If you are guilty in adult court you can spend almost your life in jail $\left[{ }_{[0-3]}\right.$, but if you are in juvenile court you could spend up to a couple of years in juvy $[\mathrm{M}+2]$. In adult court it teaches the juveniles a larger lesson and discipline ${ }_{[\mathrm{O}+4]}$ and they have a lot of time to think about what they had done $[\mathrm{O}+5]$. In response to that, the larger amount of time spent there the larger the influence [0-4]. The influence brought about in adult jail can scar the juvenile for life $[0-5] \ldots$ 


\section{References}

Crowell, A., \& Kuhn, D. (2014). Developing dialogic argumentation skills: A three-year intervention study. Journal of Cognition and Development, 15, 363-381.

Felton, M., Crowell, A., \& Liu, T. (2015). Arguing to agree: Mitigating my-side bias through consensusseeking dialogue. Written Communication, 32, 317-331.

Hemberger, L., Kuhn, D., Matos, F., \& Shi, Y. (2017). A dialogic path to evidence-based argumentive writing. Journal of the Learning Sciences, 26, 575-607.

Iordanou, K., \& Constantinou, C. (2015). Supporting use of evidence in argumentation through practice in argumentation and reflection in the context of SOCRATES learning environment. Science Education, 99, 282-311.

Kuhn, D. (2018). Building our best future: Thinking critically about ourselves and our world. New York: Wessex Learning.

Kuhn, D., \& Crowell, A. (2011). Dialogic argumentation as a vehicle for developing young adolescents' thinking. Psychological Science, 22, 545-552.

Kuhn, D., Hemberger, L., \& Khait, V. (2016). Argue with me: Argument as a path to developing students' thinking and writing (2nd ed). New York: Routledge.

Kuhn, D., \& Moore, W. (2015). Argument as core curriculum. Learning: Research and Practice, 1, 66-78.

Kuhn, D., \& Zillmer, N. (2015). Developing norms of discourse. In L. Resnick, C. Asterhan, \& S. Clarke (Eds.), Socializing intelligence through academic talk and dialogue. Washington, DC: American Educational Research Association.

Kuhn, D., Zillmer, N., Crowell, A., \& Zavala, J. (2013). Developing norms of argumentation: Metacognitive, epistemological, and social dimensions of developing argumentive competence. Cognition \& Instruction, 31, 456-496.

Lipman, M. (2003). Thinking in education. New York: Cambridge University Press.

Olson, D., \& Oatley, K. (2014). The quotation theory of writing. Written Communication, 31, 4-26.

Resnick, L.B., Michaels, S., \& O'Connor, C. (2010). How (well structured) talk builds the mind. In R. Sternberg \& D. Preiss (Eds.), From genes to context: New discoveries about learning from educational research and their applications. New York: Cambridge.

Scardamalia, M., \& Bereiter, C. (2014). Knowledge building and knowledge creation: Theory, pedagogy and technology. In R.K. Sawyer (Ed.) The Cambridge handbook of the learning sciences. New York: Cambridge University Press.

Vygotsky, L. S. (1978). Mind and society: The development of higher mental processes. Cambridge, MA: Harvard University Press. 


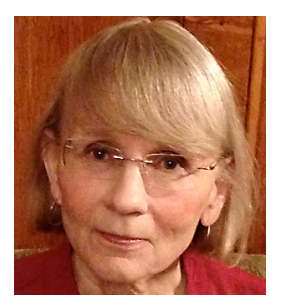

Deanna Kuhn, Professor of Psychology and Education at Teachers College Columbia University, is a leading figure in the promotion of dialog to develop students' critical thinking and writing, with a goal of preparing young people for lifelong learning, work, and citizenship. She has published in journals ranging from Psychological Review to Harvard Educational Review, and has written five major books: The Development of Scientific Thinking Skills, The Skills of Argument, Education for Thinking, Argue With Me: Argument as a Path to Developing Students' Thinking and Writing, and, most recently, Building Our Best Future: Thinking Critically About Ourselves and Our World. 